\title{
Efficacy of $75 \%$ alcohol in pretreatment of the Andersen sampler in trapping maximum airborne microbes
}

\author{
Yan Zhao $\cdot$ Jingwei Zhang $\cdot$ Shumei Wang $\cdot$ Lingqi Yu $\cdot$ Hao Yu $\cdot$ \\ Yuwen Wang $\cdot$ Lihong Feng
}

Received: 11 April 2020/ Accepted: 20 October 2020/Published online: 5 January 2021

(C) Springer Nature B.V. 2021

\begin{abstract}
The present study was conducted to evaluate the effects of the pretreatment methods and sampling time on the sampling of airborne bacteria in hospitals. Methods for the pretreatment of Andersen samplers, namely, non-sterilized, $75 \%$ ethanol and autoclaving sampled for $5 \mathrm{~min}, 10 \mathrm{~min}$ and $15 \mathrm{~min}$ in the general ward and class 1000 clean operating department, respectively, were studied. Statistical analysis was used to compare the differences in sampling results of airborne bacteria under different pretreatment methods, sampling time and environmental conditions. In the first test, the sampling results of the airborne bacteria obtained by pretreatment of the sampler with $75 \%$ ethanol and without pretreatment were not very different, and the sampling results showed a certain declining trend with the extension of the sampling time. In the second test, the pretreatment effect of autoclaving was significantly
\end{abstract}

Electronic supplementary material The online version of this article (https://doi.org/10.1007/s10453-020-09668-2) contains supplementary material, which is available to authorized users.

Y. Zhao $(\bowtie) \cdot$ J. Zhang $\cdot$ H. Yu · Y. Wang $\cdot$ L. Feng Department of Environment and Health, Tianjin Centers for Disease Control and Prevention, 6 Huayue Road, Hedong District, Tianjin, China

e-mail: kevin2002a@163.com

S. Wang $\cdot$ L. Yu

Department of Pathogen Microbiology, Tianjin Centers for Disease Control and Prevention, Tianjin, China better than that of $75 \%$ ethanol, and the sampling time had no effect on the sampling results. After removing the influencing factors of the environment, the results were consistent with the results of the second test. It was observed that the Andersen samplers should not be pretreated with $75 \%$ ethanol before airborne microbes sampling. The pretreatment should be carried out by autoclaving, and the sampling time has little effect on the sampling results.

Keywords Pretreatment methods - Hospital disinfection - Airborne microbe - Andersen sampler . Clean operating department

\section{Introduction}

Airborne transmission is one of the most frequent causes of hospital infections (Eames et al. 2009; Kozajda et al. 2019). Dangerous infectious coronavirus disease 2019 (COVID-19) spread via airborne during aerosol generating procedures (Doremalen et al. 2020), and 20\% of COVID-19 infections occurring in health care personnel in hospital of Italy (Remuzzi et al. 2020). Some studies have also reported that bacteria and viruses are present in aerosol particles (Kirby et al. 2016; Pichon et al. 2019; Núñez et al. 2017).

The airborne microbe test is a frequently used sampling method for preventing indoor infections in 
public places and hospital wards. This testing is an effective way to identify air pollution in the hospital as soon as possible and to prevent the occurrence of nosocomial infection. The total number of bacterial colonies refers to the number of collected bacterial colonies grown on the nutrient agar plate under certain conditions (such as aerobic, nutritional, $\mathrm{pH}$, temperature and time conditions) (Li et al. 2019; Harp 2018). Certain conditions refer to culture at $35-37^{\circ} \mathrm{C}$ for $48 \mathrm{~h}$ under aerobic conditions (General Administration of Quality Supervision, Inspection and Quarantine of the People's Republic of China. 2010). Therefore, it is difficult for anaerobic or micro-aerobic bacteria with special nutritional requirements and nonmesophilic bacteria to reproduce under these conditions, because the existing conditions could not satisfy the physiological requirements for their growth.

Andersen six-stage sampler is a sensitivity instrument which could size and counted airborne particle aerosols, which was of great value in controlling sources of airborne disease (Andersen 1958; Buttner et al. 1993). Andersen sampler will not be soiled or contaminated by proper handling and operation, except for very special detection studies or work with pathogenic aerosols; it does not require cleaning or sterilization between runs, and only need passing very clean air before sampling to eliminate particles that can clog the holes in the stages. However, there are numerous pathogenic aerosols in the hospital environment, and frequent sampling of airborne microbe in the hospital environment will pollute the Anderson sampler (Charifa et al. 2017; Joost et al. 2019; Sedighe et al. 2019). Therefore, before using the Anderson sampler for air sampling in a hospital environment, it is necessary to perform a proper pretreatment on the sampler (Sung et al. 2014). China's architectural technical code for hospital clean operating department and indoor air quality standard also requires aseptic operation when using the Andersen sampler for airborne microbe sampling (Ministry of Housing and Urban-Rural Development of the People's Republic of China 2013; General Administration of Quality Supervision, Inspection and Quarantine of the People's Republic of China. 2002). Pretreatment of the Andersen sampler is also part of the aseptic operation, but the current standards have not yet clearly defined the pre-treatment method of the Anderson sampler. The use of $75 \%$ ethanol as cleaning pre-treatment of the Andersen stages was introduced by manufacturers of many sampler models, often used in the daily sampling of airborne microbe in the hospital environment. Moreover, the diameter of airborne particle aerosols usually determined the number of the deposition step, in the case of Andersen multistage. However, it is often found that the sampling result of the old Anderson sampler is higher than that of the new one in our daily sampling work. Therefore, the processing effect of the pretreatment methods of Andersen sampler is worthy of attention.

Currently, little research has been performed on the effects of cleaning and disinfecting Andersen samplers on sampling. Noro et al. (1998) used an Andersen sampler to sample and count bacterial cells and airborne dust and found that a clean environment was effective in reducing airborne environmental contamination. The effect of different pretreatment methods on the sampling results of Andersen samplers has not been reported. In this study, the differences in sampling results with two types of disinfection of an Andersen sampler were compared in a general hospital ward and a class 1000 operating clean room. The effects of sampling time and disinfection methods on the sampling results of airborne microbes were discussed. Evidence is provided for selecting a reasonable sampling time and effective disinfection method for infection detection in hospitals.

\section{Methods}

The study was conducted at a general tertiary hospital in Tianjin as the experimental site. A common ward and a class 1000 operating clean room were selected randomly. Airborne microbes were sampled with Andersen six-stage sampler (QT-30, SKC, USA).

\subsection{Sampling and processing of airborne microbes}

Each level of the Andersen sampler was supported by a nutrient agar plate $(90 \mathrm{~mm}, 190530$, Tianjin Nuofan Biological Technology Co., Ltd, China) and sampled at a flow rate of $28.3 \mathrm{~L} / \mathrm{min}$. The trial flow control system consisted of a primary calibrator (4046, TSI Incorporated, USA), which controlled the sampling flow rate. For the first trial in the general ward, one Andersen sampler was sterilized with $75 \%$ ethanol, and the other Andersen sampler was not sanitized 
before sampling. For sterilization, the surface, back and sealing ring of each stage of the sampler, as well as around the air intake, were wiped with cotton balls soaked with $75 \%$ alcohol. The temperature of the general ward was $24{ }^{\circ} \mathrm{C}$, and the humidity was $55 \%$. The door and window of the general ward were closed.

For the second trial in the general ward, one Andersen sampler was sterilized with $75 \%$ ethanol in the same way as the first trial. After removing the seal ring, each stage of another Andersen sampler was individually packaged and autoclaved (HV-110, HIRAYAMA, Japan) at $102.9 \mathrm{kPa}$ and $121^{\circ} \mathrm{C}$ for $30 \mathrm{~min}$. The atmospheric conditions and background of the general ward were the same as in the first trial. For the third trial in the hospital class 1000 operating clean room, one Andersen sampler was sterilized with 75\% ethanol, and the other Andersen sampler was autoclaved at $102.9 \mathrm{kPa}$ and $121^{\circ} \mathrm{C}$ for $30 \mathrm{~min}$ before sampling.

In the three experiments, the two samplers were sampled for $5 \mathrm{~min}, 10 \mathrm{~min}$ and $15 \mathrm{~min}$. Each sampling period was repeated six times. Each sampler was sterilized or autoclaved before each sampling period. Sampling for the next cycle was performed after each sampling cycle was completed.

\subsection{Cultivation and counting of airborne microbes}

After the completion of all samplings the petri plates were incubated in a $35-37{ }^{\circ} \mathrm{C}$ incubator (LRH-250A, Guangdong Medical Instrument Factory, China) for 48 h (General Administration of Quality Supervision, Inspection and Quarantine of the People's Republic of China. 2010). Colony forming units were counted after the completion of the culture, and the results were recorded and converted to $\mathrm{CFU} / \mathrm{m}^{3}$ according to the dilution ratio and volume of the sampling gas. The reference formula is as follow:

Total bacteria in the air $\left(\mathrm{CFU} / \mathrm{m}^{3}\right)$

$=\frac{\text { Total number of bacteria on the six }- \text { sampling plate }}{28.3 \mathrm{~L} / \mathrm{min} \times \text { sampling time }}$ $\times 1000$

\subsection{Statistical analysis}

Total bacterial growth was derived from nutrient agar plates and calculated in $\mathrm{CFU} / \mathrm{m}^{3}$. All calculations were performed using Statistical Package for the Social Sciences Version 24.0 (IBM Corp., Armonk, NY, USA). As the variables of total bacterial colonies follow nonnormal distribution, a Wilcoxon rank-sum test was performed. The statistical results of the Wilcoxon rank-sum test of two independent samples were represented by the $Z$ value, and the test results of several independent samples were represented by the $\chi^{2}$ value. The testing level was $\alpha=0.05$.

\section{Results}

\subsection{Bacterial counts from first trial at general ward}

The results of first trial revealed that there was no significant statistical difference between the pretreatment with $75 \%$ ethanol and no pretreatment ( $Z=0.791, P=0.443)$. A total 642 colonies (Median) of the no pretreatment group was recorded ranging from $215 \mathrm{CFU} / \mathrm{m}^{3}$ to $3152 \mathrm{CFU} / \mathrm{m}^{3}$. A total 596 colonies (Median) of the $75 \%$ ethanol pretreatment group was recorded ranging from $217 \mathrm{CFU} / \mathrm{m}^{3}$ to $2880 \mathrm{CFU} / \mathrm{m}^{3}$. Further analysis of the results of sampling at different time periods also showed that there was no significant statistical difference between the sampling results of the two pretreatment methods $\left(Z_{5 \min }=0.961, P_{5 \min }=0.394 ; Z_{10 \text { min }}=0.801, P_{10}\right.$ $\left.\min =0.485 ; Z_{15 \min }=0.401, P_{15 \min }=0.699\right)$. With pretreatment of the Andersen air microbial sampler with $75 \%$ ethanol, no statistically significant differences were observed between different sampling periods $\left(\chi^{2}=5.801, P=0.055\right)$. When the Andersen air microbial sampler was not pretreated, the $5 \mathrm{~min}$ test results were significantly higher than those of the $10 \mathrm{~min}$ and $15 \mathrm{~min}$ tests, and the difference was statistically significant $\left(\chi^{2}=7.871, P=0.020\right)$. The test results of the first airborne bacteria sampling in the general ward are shown in Fig. 1 and Table 1 (Table S1, Supporting Information).

\subsection{Bacterial counts from second trial at general ward}

The results of second trial revealed that the airborne microbe sampling results with the sampler pretreated by autoclaving were significantly lower than those of the sampler pretreated with $75 \%$ ethanol $(Z=2.674$, $P=0.007$ ). A total 311 colonies (Median) of the 


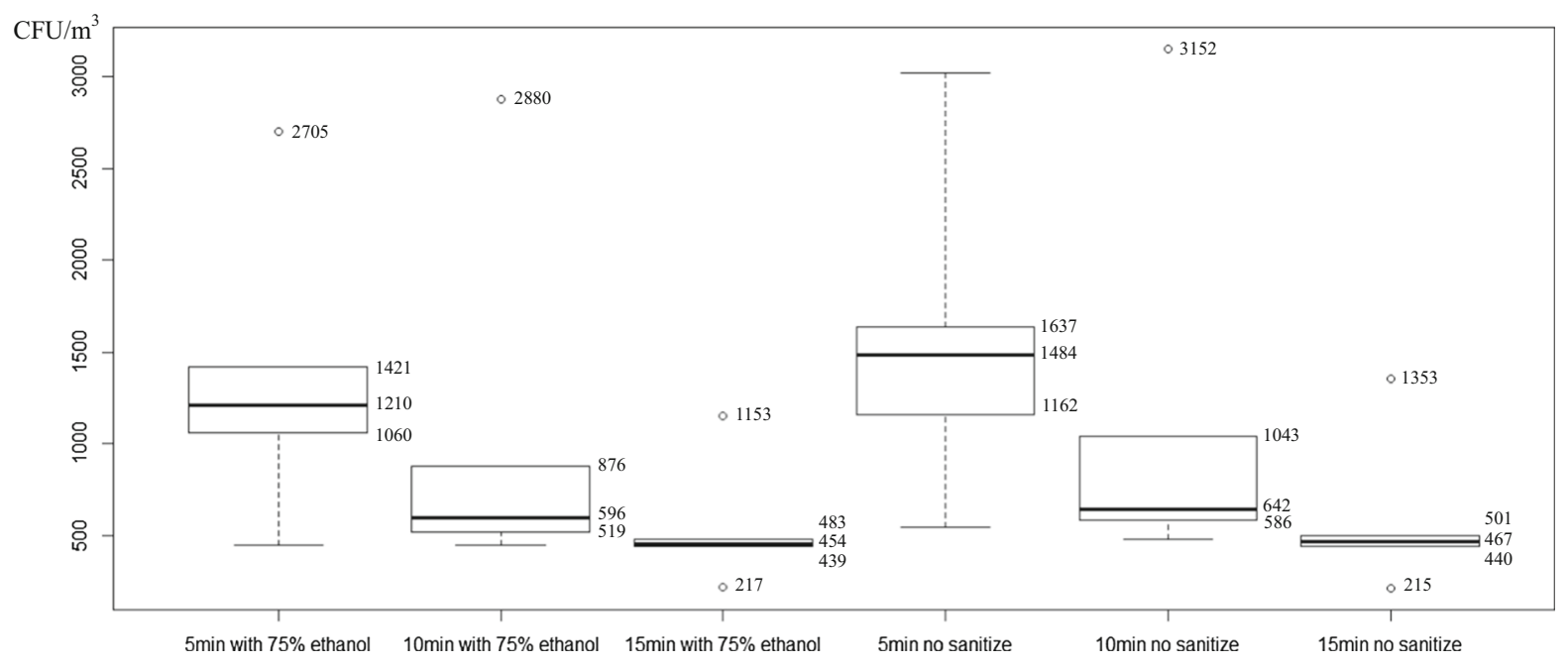

Fig. 1 Airborne bacteria sampling results of the first trial in the general ward

Table 1 The three trials results of airborne microbe sampling in hospital (M, median)

\begin{tabular}{|c|c|c|c|c|c|c|c|c|c|}
\hline \multirow[t]{2}{*}{ Time } & \multirow[t]{2}{*}{ Frequency } & \multicolumn{2}{|c|}{ No pretreatment } & \multicolumn{2}{|l|}{$75 \%$ ethanol } & \multicolumn{2}{|l|}{ Autoclave } & \multirow[t]{2}{*}{$Z$} & \multirow[t]{2}{*}{$P$} \\
\hline & & $\begin{array}{l}\text { Range (CFU/ } \\
\left.\mathrm{m}^{3}\right)\end{array}$ & $\begin{array}{l}M(\mathrm{CFU} / \\
\left.\mathrm{m}^{3}\right)\end{array}$ & $\begin{array}{l}\text { Range (CFU/ } \\
\left.\mathrm{m}^{3}\right)\end{array}$ & $\begin{array}{l}M(\mathrm{CFU} / \\
\left.\mathrm{m}^{3}\right)\end{array}$ & $\begin{array}{l}\text { Range (CFU/ } \\
\left.\mathrm{m}^{3}\right)\end{array}$ & $\begin{array}{l}M(\mathrm{CFU} / \\
\left.\mathrm{m}^{3}\right)\end{array}$ & & \\
\hline First test & 18 & $215-3152$ & 642 & $217-2880$ & 596 & $-{ }^{*}$ & $-{ }^{*}$ & 0.791 & 0.443 \\
\hline $\begin{array}{l}\text { Second } \\
\text { test }\end{array}$ & 18 & $-{ }^{*}$ & $-{ }^{*}$ & $288-1400$ & 485 & $177-799$ & 311 & 2.674 & 0.007 \\
\hline Third test & 18 & $-^{*}$ & - $^{*}$ & $179-1152$ & 298 & $5-36$ & 15 & 5.130 & 0.000 \\
\hline
\end{tabular}

*Indicates that no such result

autoclaving group was recorded ranging from $177 \mathrm{CFU} / \mathrm{m}^{3}$ to $799 \mathrm{CFU} / \mathrm{m}^{3}$. A total 485 colonies (Median) of the $75 \%$ ethanol pretreatment group was recorded ranging from $288 \mathrm{CFU} / \mathrm{m}^{3}$ to $1400 \mathrm{CFU} / \mathrm{m}^{3}$. Regarding sampling at different time intervals, the autoclaved sampler's results of the airborne microbe sampling for $5 \mathrm{~min}$ and $10 \mathrm{~min}$ were significantly lower than the results of the sampler pretreated with $75 \%$ ethanol, but the results of sampling for $15 \mathrm{~min}$ were no statistically differences $\left(Z_{5} \min =2.882, P_{5}\right.$ $\min =0.004 ; Z_{10 \mathrm{~min}}=2.242, P_{10 \mathrm{~min}}=0.025 ; Z_{15} \mathrm{~min}$ $\left.=0.961, P_{15} \min =0.337\right)$. The $5 \mathrm{~min}$ sampling result of the pretreatment with $75 \%$ ethanol was significantly greater than that of the other two periods $\left(\chi^{2}=12.538\right.$, $P=0.002$ ). For the pretreatment of the Andersen air microbial sampler by autoclaving, there was no statistically significant difference in the sampling results at different time points $\left(\chi^{2}=2.356\right.$,
$P=0.308)$. The test results of the second airborne bacteria sampling in the general ward are shown in Fig. 2 and Table 1 (Table S2, Supporting Information).

\subsection{Bacterial counts in class 1000 operation clean room}

The results of the class 1000 operation clean room revealed that the airborne microbe sampling results of the sampler pretreated by autoclaving were significantly lower than those of the sampler pretreated with $75 \%$ ethanol $(Z=5.130, P=0.000)$. A total 15 colonies (Median) of the autoclaving group was recorded ranging from $5 \mathrm{CFU} / \mathrm{m}^{3}$ to $36 \mathrm{CFU} / \mathrm{m}^{3}$. A total 298 colonies (Median) of the $75 \%$ ethanol pretreatment group was recorded ranging from $179 \mathrm{CFU} / \mathrm{m}^{3}$ to $1152 \mathrm{CFU} / \mathrm{m}^{3}$. The autoclaved 


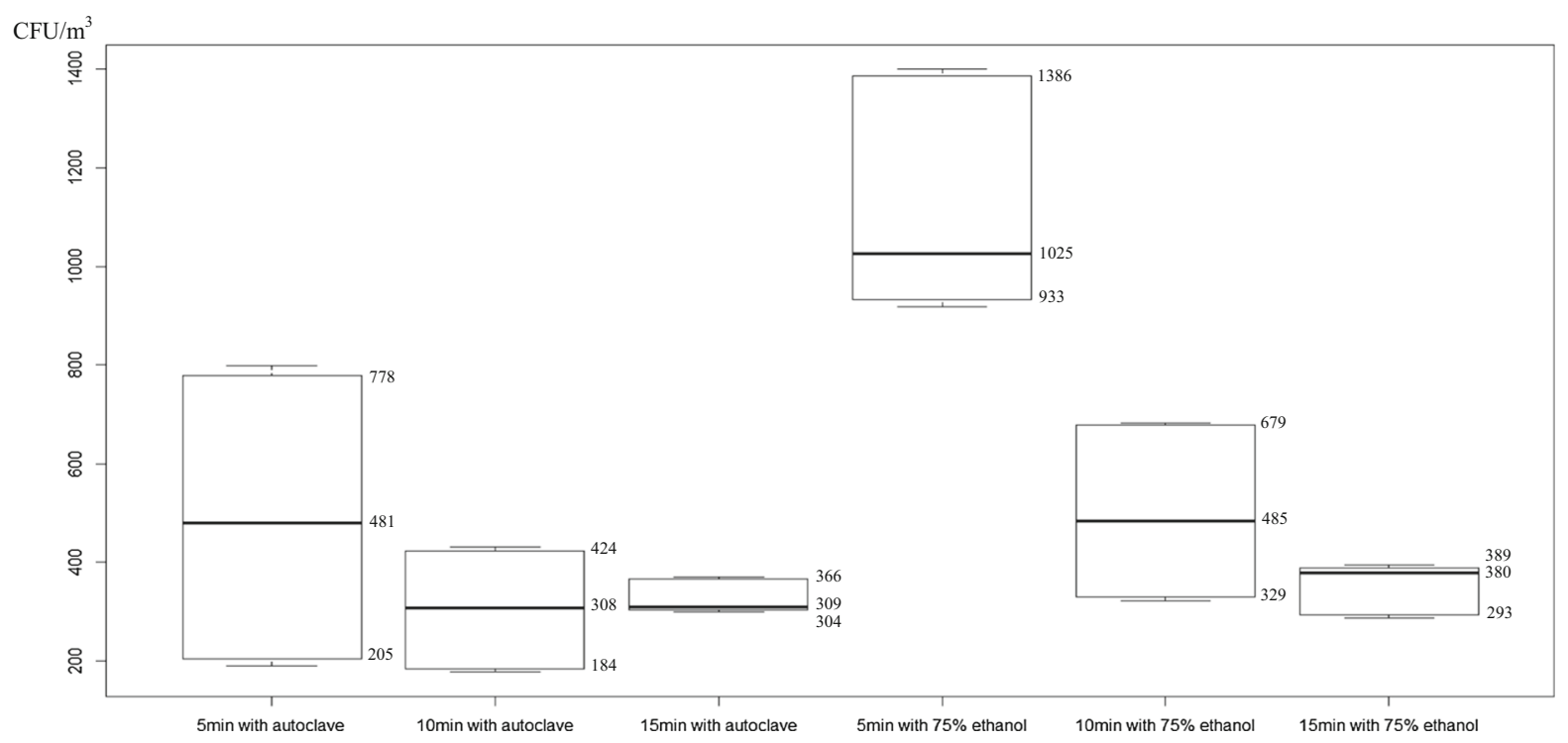

Fig. 2 Airborne bacteria sampling results of the second trial in the general ward

sampler's sampling results of $5 \mathrm{~min}, 10 \mathrm{~min}$ and 15 min were significantly lower than the results of the sampler pretreated with $75 \%$ ethanol $\left(Z_{5 \text { min }}=2.882\right.$, $P_{5 \min }=0.004 ; Z_{10 \mathrm{~min}}=2.892, P_{10 \mathrm{~min}}=0.004 ; Z_{15}$ $\left.\min =2.892, P_{15} \min =0.004\right)$. The sampling result of $5 \mathrm{~min}$ in the class 1000 operating clean room of the pretreatment with $75 \%$ ethanol was significantly higher than that in the other two periods $\left(\chi^{2}=15.174, P=0.001\right)$. For the sampler pretreated by autoclaving, there was no statistically significant difference in the sampling results at different time points $\left(\chi^{2}=3.797, P=0.150\right)$. The test results of the airborne bacteria sampling in the hospital class 1000 operating clean room are shown in Fig. 3 and Table 1 (Table S3, Supporting Information).

The above three trials showed that $75 \%$ alcohol could not make the Anderson sampler achieve the expected pretreatment effect. Using the autoclaved Anderson sampler, sampling for 5 min could correctly reflect the airborne microbes' pollution level of the detected environment.

\section{Discussion}

Ethanol (75\%) is a widely used medium-effect disinfectant. It has a good sterilizing effect on most bacteria and viruses, but it has no obvious sterilizing effect on bacterial spores (Xue 2010). In the first trial, there is little difference between the results of the pretreatment of the Andersen air microbial sampler with $75 \%$ ethanol and the results of the non- sanitized sampler. The test results showed that $75 \%$ ethanol has a limited ability to rapidly sterilize the Andersen's air microbial sampler. Other studies have found similar situations (Stewart et al. 2019; Sui et al. 2012). For example, in the observation of the disinfection effect of different chemical disinfectants, it was found that the microbial yield of the surface of the object disinfected by $75 \%$ ethanol was significantly lower than that of other chemical disinfectants. However, some previous research conclusions were contrary to ours. Sandle and Satyada (2015) pointed out the efficiency of $70 \%$ isopropyl alcohol for disinfection of the Andersen sampler and Trissel et al. (2007) indicated that repeated disinfection with IPA decreased the contamination rate. This may be because isopropyl alcohol contains two methyl groups, which greatly enhance its lipophilicity, while alcohol contains only one ethyl group. Ethyl is less lipophilic than methyl. $75 \%$ ethanol did not reflect the expected disinfection effect, which may be related to the external temperature (Mohanta and Jana 2016), defects with the disinfectant or the fact that the $75 \%$ ethanol disinfectant was not suitable for disinfection. In the first test, we also found that the sampling results showed a certain downward trend with increasing sampling time. 


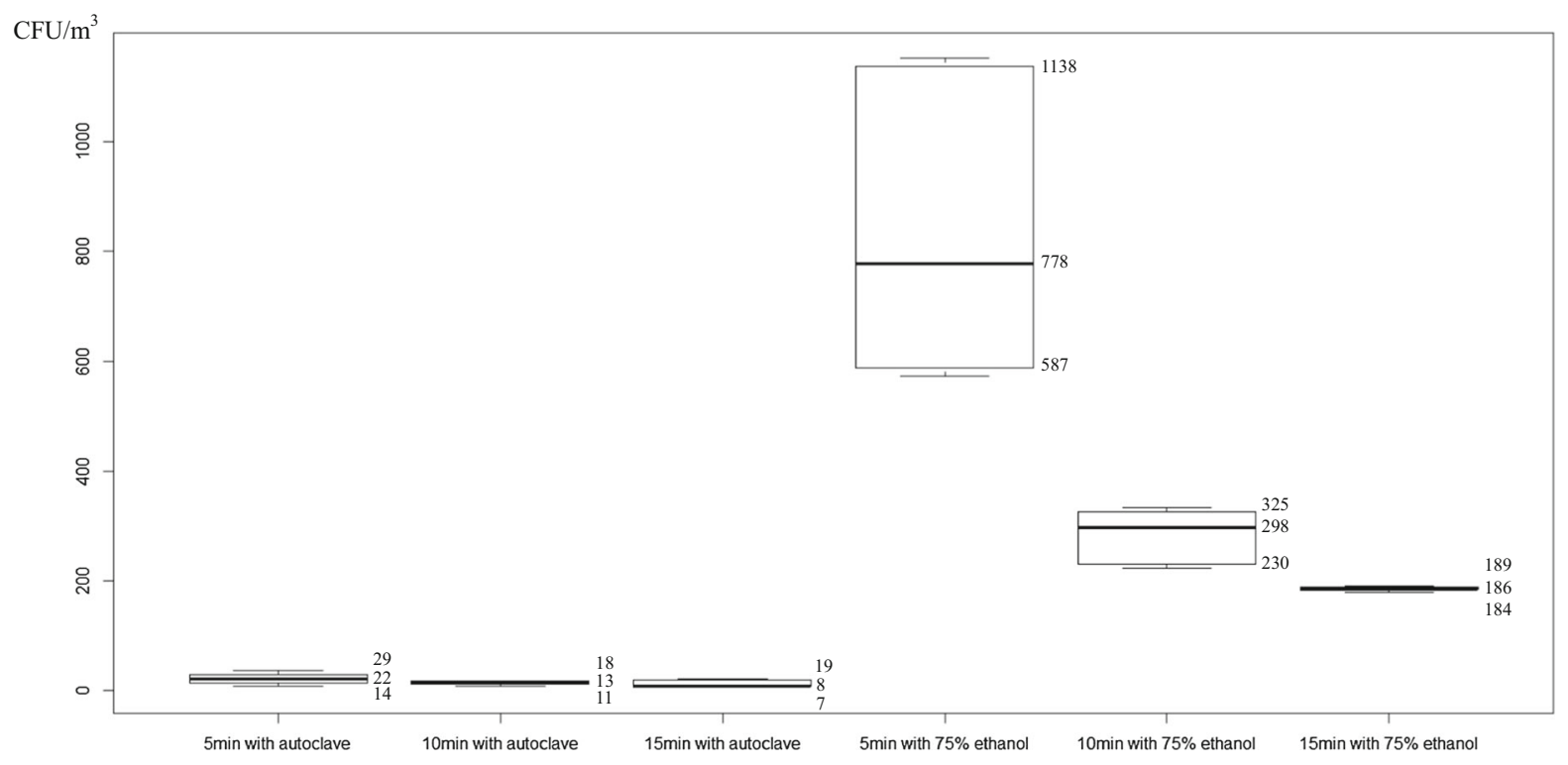

Fig. 3 Airborne bacteria sampling results of the third trial in the hospital class 1000 operating clean room

The second trial results showed that the pretreatment effect of autoclaving was significantly better than that of $75 \%$ ethanol. Relevant research has indicated the same results; Lin et al. (2018) sterilized Bacillus subtilis spores loaded on an N95 filtering face piece respirator with different disinfection methods, and the results showed that the effect of hightemperature autoclaving was higher than that of other disinfection methods. Some studies have observed the morphology of live bacteria disinfected by $75 \%$ ethanol and disinfected by autoclaving with field emission scanning electron microscopy. After disinfection with $75 \%$ ethanol, it was found that the number of live bacteria on the surface of the sample was still large, and the shape of the bacteria was still relatively complete. However, after high-pressure steam sterilization, the number of viable cells on the surface of the sample was small, and the morphology was destroyed (Garibaldi et al. 2017; Darshan et al. 2019; Tan et al. 2013).

Different from the results of the $75 \%$ alcohol pretreatment in the first trial, this experiment revealed that the sampling time had an effect on the results with the $75 \%$ ethanol pretreatment but had little effect on the results with the autoclaving pretreatment. This situation may be because the two experiments were not performed at the same time, and the air pollution conditions of the general ward may have changed.
However, the tendency of the total number of bacterial colonies to decrease as the sampling time increased was still apparent. The results of the second trial preliminarily determined that $75 \%$ ethanol is not suitable for disinfecting the Andersen air microbial sampler. But, the influence of the change in the environment during the sampling time should not be ignored. It was necessary to more accurately analyze the pretreatment effects of autoclaving and $75 \%$ ethanol on the sampling results while eliminating the factors of sampling environmental pollution conditions as much as possible.

The sampling environment could be effectively controlled, when the airborne bacteria sampling test was carried out in the class 1000 operating clean room and the self-cleaning degree of the sampler after pretreatment would directly affect the sampling result. The results of the third test showed that the pretreatment effect of autoclaving on the Andersen sampler is significantly better than that of the sampler using $75 \%$ ethanol and further proved that the length of the sampling time has little effect on the results after autoclaving.

It was found that the sampling results of airborne microbes greatly affected by the self-cleaning degree of the Andersen sampler. If the Andersen sampler is not sterilized effectively before sampling, the authenticity of the sampling results will be seriously affected. 
Although the number of samples in this study is limited, it still can be suggested that the sampling in hospital environments, for the determination of the airborne microbe, should require a more rigorous pretreatment through autoclaving. However, the process of autoclaving pretreatment is complicated, so it is necessary to prepare several Anderson samplers for autoclaving pretreatment at the same time before sampling airborne microbes in multiple hospital wards.

In conclusion, this study found that the Andersen sampler needs to be pre-processed before sampling the airborne bacteria in the hospital indoor environment. Ethanol $(75 \%)$ has a poor pretreatment effect on the sampler and should be avoided in daily sampling. Autoclaving has a good pre-treatment effect on the Andersen sampler, and could be widely applied to the pretreatment of the Andersen sampler before indoor airborne bacteria sampling (Table 1). However, since this study was only conducted in one hospital, it is inevitable that the results will have certain limitations. Therefore, further expansion of the scope of the experiment will help strengthen hospital disinfection management work. The effective pretreatment method for sampler disinfection should be correctly selected, which will also provide an accurate basis for more effective protection of the indoor air quality of the hospital and could be useful for operators who do not have sufficient scientific and cultural knowledge on aerobiological monitoring.

Acknowledgements We acknowledge the contribution of all the members who participated in the sampling and analysis.

\section{Compliance with ethical standards}

Conflict of interest The authors declare that they have no conflict of interest.

Ethical approval No ethical approval was required or sought for the study, because there was no interaction or intervention with human participants.

\section{References}

Andersen, A. A. (1958). New sampler for the collection, sizing, and enumeration of viable airborne particles. Journal of Bacteriology, 76, 471-484.

Buttner, M. P., \& Stetzenbach, L. D. (1993). Monitoring airborne fungal spores in an experimental indoor environment to evaluate sampling methods and the effects of human activity on air sampling. Applied and Environment Microbiology, 59(1), 219-216.

Charifa, Z., Hans, D. S., Wim, C., \& Alexa, L. (2017). A scoping review on bio-aerosols in healthcare and the dental environment. PLOS ONE, 12(5), e0178007.

Darshan, V., Indushekar, K. R., Saraf, B. G., Sheoran, N., Sharma, B., \& Sardana, D. (2019). A comparison of decontamination methods of tried-in preformed metal crowns: an in-vivo study. European Archives of Paediatric Dentistry, 20(6), 537-544.

Doremalen, N. V., Bushmaker, T., Morris, D. H., Holbrook, M. G., Gamble, A., Williamson, B. N., et al. (2020). Aerosol and surface stability of SARS-CoV-2 as compared with SARS-CoV-1. New England Journal of Medicine, 382(16), 1564-1567.

Eames, I., Tang, J. W., Li, Y., \& Wilson, P. (2009). Airborne transmission of disease in hospitals. Journal of the Royal Society, Interface, 6, S697-S702.

Garibaldi, B. T., Reimers, M., Ernst, N., Bova, G., Nowakowski, E., Bukowski, J., et al. (2017). Validation of autoclave protocols for successful decontamination of category a medical waste generated from care of patients with serious communicable diseases. Journal of Clinical Microbiology, 55(2), 545-551.

General Administration of Quality Supervision, Inspection and Quarantine of the People's Republic of China. (2002). Indoor air quality standard (GB/T 18883-2002). Beijing: Standards Press of China.

General Administration of Quality Supervision, Inspection and Quarantine of the People's Republic of China. (2010). Test method for airborne microbe in clean room (zone) of the pharmaceutical industry (GB/T 16293-2010). Beijing: Standards Press of China.

Harp, J. H. (2018). A clinical test to measure airborne microbial contamination on the sterile field during total joint replacement: method, reference values, and pilot study. $J B$ JS Open Access., 3(3), e0001.

Joost, H., Corianne, M., Nikki, K., Jordy, P. M. C., Mohammad, R. G., Shaheen, M., et al. (2019). Risk assessment after a severe hospital-acquired infection associated with carbapenemase-producing seudomonas aeruginosa. JAMA Netw Open., 2(2), e187665.

Kirby, A. E., Streby, A., \& Moe, C. I. (2016). Vomiting as a symptom and transmission risk in norovirus illness: evidence from human challenge studies. Plos one, 11, e0143759.

Kozajda, A., Jeżak, K., \& Kapsa, A. (2019). Airborne Staphylococcus aureus in different environments-a review. Environmental Science and Pollution Research International, 26(34), 34741-34753.

Li, H., Zhou, X. Y., Yang, X. R., Zhu, Y. G., Hong, Y. W., \& Su, J. Q. (2019). Spatial and seasonal variation of the airborne microbiome in a rapidly developing city of China. Science of the Total Environment, 665, 61-68.

Lin, T. H., Tang, F. C., Hung, P. C., Hua, Z. C., \& Lai, C. Y. (2018). Relative survival of Bacillus subtilis spores loaded on filtering facepiece respirators after five decontamination methods. Indoor Air, 28(5), 754-762.

Ministry of Housing and Urban-Rural Development of the People's Republic of China. (2013). Architectural 
technical code for hospital clean operating department (GB 50333-2013). Beijing: China Architecture \& Building Press.

Mohanta, D., \& Jana, M. (2016). Effect of ethanol concentrations on temperature driven structural changes of chymotrypsin inhibitor 2. The Journal of Chemical Physics, 114(16), 165101.

Núñez, A., Amode, P. G., Ferencova, Z., Rastrojo, A., Guantes, R., García, A. M., et al. (2017). Validation of the hirst-type spore trap for simultaneous monitoring of prokaryotic and eukaryotic biodiversities in urban air samples by nextgeneration sequencing. Applied and Environmental Microbiology, 83(13), e00472-17.

Noro, A., Suyama, Y., Takahashi, E., Chattin, B. R., Hirai, Y., Takahashi, K., \& Ishikawa, T. (1998). The effectiveness of the "Clean-Area-System" for infection control in the dental clinic. The Bulletin of Tokyo Dental College, 39(1), $15-24$.

Pichon, J., Chouaid, C., Marc, E., \& Voiriot, G. (2019). Respiratory isolation in suspected tuberculosis with negative direct sputum examination. Revue des Maladies Respiratoires, 36(3), 396-404.

Remuzzi, A., \& Remuzzi, G. (2020). COVID-19 and Italy: What next? The Lancet, 395, 1225-1228.

Sandle, T., \& Satyada, R. (2015). Assessment of the disinfection of impaction air sampler heads using $70 \%$ IPA, as part of cleanroom environmental monitoring. European Journal of Parenteral and Pharmaceutical Sciences., 20(3), 94-99.

Sedighe, K. R., Hatam, G., Bahram, N., Heidar, B., \& Arezoo, C. (2019). Study on the relationship between the concentration and type of fungal bio-aerosols at indoor and outdoor air in the children's medical center, Tehran, Iran. Environmental Monitoring and Assessment, 191(2), 48.

Stewart, S., Robertson, C., Manoukian, S., Haahr, L., Mason, H., Mcfarland, A., et al. (2019). How do we evaluate the cost of nosocomial infection? The ECONI protocol: an incidence study with nested case-control evaluating cost and quality of life. British Medical Journal Open, 9(6), 1-10.

Sui, Y. S., Wan, G. H., Chen, Y. W., Ku, H. L., Li, L. P., Liu, C. H., \& Mau, H. S. (2012). Effectiveness of bacterial disinfectants on surfaces of mechanical ventilator systems. Respiratory Care, 57(2), 250-256.

Sung, H. H., Hyun, H. P., \& Chung, S. Y. (2014). Analysis of variation in total airborne bacteria concentration to assess the performance of biological safety cabinets in microbial laboratories. Safety and Health Work, 5(1), 23-26.

Tan, S. P., McLoughlin, P., O’Sullivan, L., Prieto, M. L., Gardiner, G. E., Lawlor, P. G., \& Hughes, H. (2013). Development of a novel antimicrobial seaweed extract-based hydrogel wound dressing. International Journal of Pharmaceutics, 456(1), 10-20.

Trissel, L. A., Gentempo, J. A., Saenz, L. M., Woodard, M. Y., \& Angeles, C. H. (2007). Effect of two work practice changes on the microbial contamination rates of pharmacycompounded sterile preparations. American Journal of Health System Pharmacy, 64(8), 837-841.

Xue, G. B. (2010). Technical standard for disinfection of public place. Shanghai: Standards Press of China. 